\title{
Sarah Chevalier \\ Caregiver responses to the language mixing of a young trilingual ${ }^{1}$
}

\begin{abstract}
The situation once described by Hoffmann (1985), in which children grow up exposed to three languages from an early age, is a reality for an increasing number of families. In Europe - as elsewhere - greater mobility is leading to greater numbers of mixed-language couples (Piller 2002), and, by extension, multilingual families. For such families, questions concerning the acquisition and maintenance of three or more languages in a natural environment are of direct relevance. Researchers in bilingualism have already pointed out the importance of social context for the acquisition of two languages in childhood, focusing in particular on the quantity and quality of exposure to the languages (De Houwer 1990; Döpke 1992; Okita 2002; Lanza 2004) or the prestige of the languages (Lambert 1977). In this paper, I will make use of the insights gained by such researchers and test them in a trilingual setting. The paper will focus mainly on one aspect, namely the conversational style of parents and caretakers. The data come from research being carried out in Switzerland and consist of 33 interviews with multilingual families, as well as case studies of two trilingual children. The findings attest to the importance of conversational style, but at the same time indicate that a number of further factors are also of great significance.
\end{abstract}

Keywords: caretaker, conversational style, language acquisition, one-parentone-language, trilingualism

Sarah Chevalier: University of Zurich, English Department, Plattenstrasse 47, 8032 Zurich, Switzerland, e-mail: sarah.chevalier@es.uzh.ch

\section{Introduction}

The situation once described by Hoffmann (1985), in which children grow up exposed to three languages from an early age, is a reality for an increasing

1 This idea was explored in preliminary fashion with a small part of the data used here in Chevalier (2008). 
number of families. Greater mobility is leading to greater numbers of mixedlanguage couples (Piller 2002) and, by extension, multilingual families (Wang 2008). For such families, questions concerning the acquisition and maintenance of three or more languages in a natural environment are of direct relevance, and in the last decade the issue has also received growing scholarly attention. A number of recent works focus on or provide some information about the relationship between language input and the language development of young trilingual children, notably Barnes (2006, 2011), Cruz-Ferreira (2006), Dewaele (2000, 2007), Kazzazi (2007, 2011), Montanari (2005, 2010), Quay (2001, 2008) and Wang (2008). The present paper concentrates on one particular aspect of this relationship, namely the influence of caregiver discourse styles on early trilingual development.

One factor identified in the promotion of early bilingualism is the way in which parents react when young children do not use the language spoken by the parent (also called 'language mixing' by Lanza 2004 [1997]: 215-216). To what extent do parents allow this, to what extent do they attempt to promote their own language? Parental responses to a child's use of the non-parental language have been categorised by Döpke (1992) and Lanza (2004). In addition to the findings of these two studies, further bilingualism research has given evidence of the importance of particular parental responses in promoting the parental languages - and thus bilingualism (Kasuya 1998; Juan-Garau \& PérezVidal 2001); note, however, that Nicoladis \& Genesee (1998) found no correlation between parental responses and children's language choice in the following turn. With regard to trilingual language acquisition studies, which are still relatively few, we can observe in Quay (2001) and Montanari (2005) parental acceptance of the young children's utterances in a non-parental language, and the children's overall or increasing preference for the community language.

The present paper contributes to this specific question in multilingual language acquisition with an in-depth analysis of caregiver responses to the language mixing of a two-year-old growing up with three languages. It firstly describes the subject and her language input (Section 2), then outlines the child's language choices with each of her three main caregivers (Section 3). Section 4 gives a detailed description of the method of analysis, which is based on the models of Döpke (1992) and Lanza (2004). This is followed by an analysis of the responses of the main interlocutors of the child's two non-dominant languages: her father (Section 5) and her aunt (Section 6). I conclude by discussing correlations between these responses and the child's trilingual language production (Section 7). 


\section{Data}

\subsection{The subject and her language input}

The subject, Lina, ${ }^{2}$ lives in German-speaking Switzerland and is growing up with a Swiss mother who speaks Swiss German to her, a Belgian father who speaks French to her, and an American aunt who visits approximately twice a week and speaks to her in English. In addition, the parents speak English to each other. Lina has thus heard all three languages regularly from birth. All three caregivers can and do communicate with other adults in all the three languages concerned except Lina's aunt who, although she speaks fluent Swiss German (and uses it with Lina's mother), does not speak French. The adults are consistent to a high degree in speaking their own language to Lina. In the dyadic recordings (described below), Lina's mother produced 955/970 turns uniquely in Swiss German (98 percent) when in conversation with her daughter. Her father produced 876/983 turns uniquely in French (89 percent), and her aunt produced 1,162/1,166 turns uniquely in English (99.7 percent). Lina has a great deal of exposure to Swiss German as her mother is the full-time caregiver and Swiss German is the language of the environment. Accordingly, she has considerably less, and approximately equal, exposure to French and English although more interaction in French. She interacts with her French-speaking father in the evenings and at weekends - and in the same period hears her parents speaking English. She interacts with her aunt only about twice a week, usually for a couple of hours each time.

\subsection{Data collection and transcription}

The data used for the study reported on here come from monthly recordings done from just after Lina's second birthday to just after her third, resulting in twelve sets of recordings. Each set consists of four recordings: child + mother, child + father, child + both parents, and child + aunt. The caregivers were asked to make half-hour audio recordings of their usual interactions with Lina. The recordings were made on a small, professional digital recorder (M-Audio MicroTrack 2496), which was placed somewhere unobtrusive. The parents were asked to record without the child realising, if possible. The decision to use a small audio-recorder, as opposed to a video-recorder, was made for the sake of unobtrusiveness. It should be mentioned, however, that this method has the disad-

2 All names are pseudonyms. 
vantage of not capturing non-verbal communication strategies, such as gestures (Doherty-Sneddon 2003; Kendon 2004). The recordings thus consist of various activities: playing, book-reading, mealtimes, getting ready for bed routines, and

so on. For each dyadic recording, a quarter of an hour close to the beginning of the recording was transcribed, resulting in just over nine hours of transcribed speech. The results and analyses presented here are based on these transcriptions.

The transcription conventions are based on CHAT, Codes for the Human Analysis of Transcription (MacWhinney 2011). These are listed in the appendix. Note that although not a CHAT convention, in this paper the three languages are represented in the following manner in the numbered examples: Swiss German is in small capitals, French is italicised and English is in bold. Words which could belong to two languages are doubly marked unless they occur in an utterance otherwise entirely in one of the two languages; in such cases, they are coded as belonging to the language of the rest of the utterance. Utterances which were not considered language-specific are unmarked.

In addition to the recordings, six visits to the family were made. These were undertaken in order to observe the family interacting, to become familiar with the child's environment (books, toys, etc.) so as to understand the recordings better, as well as to ask the parents details about language input and language development.

\section{Language choice}

Lina is dominant in Swiss German, her maternal language and the language of the community. A comparison of utterances uniquely in Swiss German, French and English reveals that Lina produced 884/910 utterances in Swiss German when in conversation with her mother (97 percent). She produced less French and English: in conversation with her father, Lina produced only 108/819 utterances in French (13 percent), while with her aunt, she produced 483/890 utterances in English (54 percent). That Lina generally spoke her maternal language with her mother is, given the language exposure patterns, only to be expected. However, since her exposure to French and English was approximately equal, and since she in fact had more interaction in French than in English, an explanation is needed for why Lina produced considerably more English than French. This question is explored with an analysis of Lina's father's and aunt's responses to her language mixing. 


\section{Responses to mixing: theoretical frame}

In this section I explain how I have worked with the models of Lanza (2004), and to a lesser extent Döpke (1992). Lanza identified five 'parental discourse strategies' (2004: ch. 6) following a child's use of the non-parental language. For example, if the parent is a speaker of English and the child utters the French lait ('milk'), the parent might 1) express incomprehension of the child's utterance (e.g. what?), 2) express a guess as to what the child could mean (e.g. do you want milk?), 3) repeat it in the target language (e.g. milk), 4) simply move on with the conversation (e.g. I'll get you some) or 5) switch to the language used by the child (e.g. tu veux du lait? 'do you want some milk?'). Lanza classified these five responses along a continuum (2004: 268), in which certain responses contribute to the creation of a monolingual context, while others help create a bilingual context. In a monolingual context, the child feels constrained to use the parental language, while in a bilingual one, the child feels free to use any language.

\section{Monolingual context}

Minimal grasp

Expressed guess

Adult repetition

Move on strategy

Code switching

Bilingual context

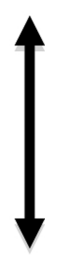

Figure 1: From a monolingual context to a bilingual context.

Döpke made a similar categorisation, from which I adopt her 'request for translation' (1992: 66) response, which I call 'instruction to translate'. In addition, I make use of her distinction between different types of adult repetition (her term is 'translation' [1992: 63-64]). Thus, in the present study, responses to language mixing fall into six basic types: instructions to translate plus the five categories identified by Lanza. These six types are described in detail below.

\subsection{Instruction to translate}

An instruction to translate is arguably the most constraining response to a child's use of a non-target language because it is usually unambiguous: the 
child understands that her language choice has been deemed inappropriate. Example (1) illustrates a typical instruction to translate:

(1) Lina (age: $2 ; 6.2)^{3}$ and aunt

@Situation: playing card game 'memory'

*LIN: HUND.

\%eng: dog.

*AUN: what does Shelly say?

\%res: instruction to translate

*LIN: dog.

\%pho: [dog $]^{4}$

This category is used by Döpke (1992: 66) and Kasuya (1998: 333). It does not exist separately in Lanza's model but rather falls under minimal grasps (see example [38] in Lanza 2004: 267, which is similar to [1] above).

Also included in the present study as instructions to translate are cases in which the adult prompts a translation by giving the initial phoneme(s) of a word, or the initial word of a multiword expression in the target language, as in example (2) below:

(2) Lina (age: 2;6.2) and aunt

@Situation: playing card game 'memory'

* $\mathrm{AUN}$ : what is it?

*LIN: (sCH)NÄGG.

\%eng: snail.

*AUN: yea:h, and what does Shelly say?

\%res: instruction to translate

${ }^{\star}$ LIN: (SCH)NÄGG.

*AUN: what? [>] $\mathbf{s}<\mathbf{n}>+. .$.

\%res: instruction to translate

*LIN: [<]<sn>a:il.

*AUN: yea:h. high five. very good.

While the aunt's what? is a minimal grasp, it is immediately followed - and thus overridden - by the prompt sn... Note that the aunt only needs to give the first phoneme /s/ before the child starts to translate.

3 Years;months.days.

4 Phonological transference from Swiss German. For a description of voiceless obstruents in Swiss German, see Schmid (2010: 1). 


\subsection{Minimal grasp}

The next most constraining response, namely minimal grasps like what?, huh? or I don't understand can be ambiguous. With such responses, it is not always clear what the trouble spot is (Lanza 2004: 270). It may lie in the form, the content or even simply the level of loudness of the utterance. If the problem lies in the form, this may be the choice of language, but it could also be the child's non-adult-like version of the item in question. This can be observed in example (3), where Lina's mother clearly cannot understand the child's first rendering of the French cassé ('broken') since Lina pronounces it in a strong Swiss German accent:

(3) Lina (age 2;1.9) and mother

@Situation: making a toy staircase out of magnets which then fall apart *LIN: cassé.

\%eng: broken.

\%pho: ['k ${ }^{\mathrm{h}}$ ase]

*MOT: hä?

\%eng: huh?

\%res: minimal grasp

*LIN: cassé.

\%pho: closer to French pronunciation

*MOT: JA, KAPUTT.

\%eng: yes, broken.

The following is an example of a minimal grasp in which the child perceives (or chooses to perceive) the trouble spot as being the content:

(4) Lina (age 2;5.3) and father

@Situation: making objects out of play dough

*LIN: ça CHÄs, xxx.

\%eng: that cheese, $\mathrm{xxx}$.

^FAT: ça c'est quoi?

\%eng: what's that?

\%res: minimal grasp

*LIN: GÄLL?

\%eng: isn’t it?

\%com: tag belongs to Lina's first utterance

*LIN: KNÄT.

\%eng: play dough. 
Here, Lina states that her play dough creation is 'cheese' in the non-target language. Her father queries this with a minimal grasp, and Lina responds by continuing in Swiss German and stating that the material is play dough. She does not respond to the minimal grasp as a cue to change languages.

Minimal grasps may involve a feigned lack of comprehension, as a conscious strategy, as well as a real lack of comprehension, as we saw in example (3) (although note that Döpke 1992: 65 excludes instances of real incomprehension). Both may in fact promote the use of the caregiver language if the child responds to them as a cue to switch languages (cf. example [21]). However, sometimes it suffices that the child repeat her utterance in the non-target language for the adult to be satisfied. In such cases, minimal grasps cannot be said to promote the use of the adult's language, and thus multilingualism. Therefore, it is important to take into account the continuation of the exchange in order to see how the minimal grasps are functioning in a particular dyad (see section 4.9). While instructions to translate are generally unambiguous, with minimal grasps an examination of the child's responses to them is imperative, since these reveal how the child is interpreting the minimal grasps - and thus the extent to which these actually constrain her to use of the adult's language (Lanza 2004: 270).

We should further note that sometimes the same word may or may not be a minimal grasp, depending on the intonation. In example (5), Lina's father's use of quoi? ('what') with falling intonation (indicated by the sign $\downarrow$ ) indicates that he is trying to work out the referent of Lina's utterance, and not that he has not understood her:

(5) Lina (age 2;1.6) and father

@Situation: looking at a picture book

^FAT: et Juliette, qu'est-ce qu'elle fait?

\%eng: and Juliette, what's she doing?

*LIN: DA.

\%eng: there.

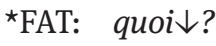

\%eng: what $\downarrow$ ?

\%res: moving on

*LIN: DA.

*FAT: elle se brosse les dents?

\%eng: she's brushing her teeth?

\%res: moving on

*LIN: DA. 
^FAT: oui, elle se brosse les dents, hein?

\%eng: yes, she's brushing her teeth, huh?

\%res: moving on

The quoi? ('what') uttered by Lina's father here was classified as moving on rather than a minimal grasp. While a rising intonation on quoi would indicate (feigned) lack of comprehension, the falling intonation of this utterance shows that the father is trying to get the child to explain what she means by $d a$ ('there'). This interpretation is reinforced by the fact that as the conversation continues, we see that the father tries to guess what 'there' could refer to.

\subsection{Expressed guess}

The expressed guess is the third response that I term 'constraining', along with instructions to translate and minimal grasps. These strategies are constraining because the adult queries the child's utterance and requires her to respond to the query in some way. One point must be noted at this junction, namely that for these strategies to be constraining, the child must be given time to reply (cf. Lanza 2004: 271). If this is not the case, the force of the response is greatly reduced, if not eliminated. This can be seen in the following example, in which Lina's aunt responds to Lina's use of Swiss German firstly with an expressed guess, but then immediately asks her a different question:

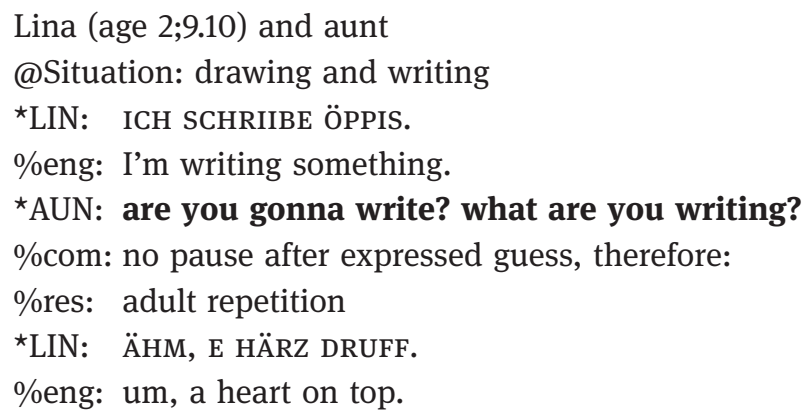

In this example, Lina was not given time to reply to the expressed guess. Therefore, the aunt's response was not coded as an expressed guess but rather as an adult repetition (see below). The time given to reply was (arbitrarily) set at a minimum length of one second. This procedure was also applied to the other two constraining strategies. 


\subsection{Adult repetition}

A response in which the caregiver translates at least one lexical item of the child's utterance in his or her next turn was counted as adult repetition:

(7) Lina (age 2;9.10) and aunt

@Situation: drawing and writing

*LIN: NAME SCHRIIBE.

\%eng: write name.

*AUN: yeah you can write, but what colour are the hearts, are they red or blue? hm?

\%res: adult repetition

In addition, clear cases of an adult translating the child's utterance, even in a later turn, were also counted as adult repetition. This can be observed in the following example. (Here and in a few other examples, the turns are numbered in order to facilitate the discussion.)

(8) Lina (age 2;6.3) and father

@Situation: looking at a picture book

*LIN: GUMP [/] GUMPISEILI. (1)

\%eng: skip [/] skipping rope.

^FAT: un GUMPISEILI. (2)

\%eng: a skipping rope.

*LIN: JA. (3)

*FAT: ça ça s'appelle une corde à sauter Lina. (4)

\%eng: that's called a skipping rope Lina.

\%res: adult repetition

In this example, Lina firstly names an object ('skipping rope'). Her father codeswitches and repeats the name in Swiss German. Lina confirms her father's repetition, thus the two middle utterances, (2) and (3), form an insertion sequence of confirmation. In (4), the father then returns to the child's original utterance to repair the form, providing the word in French. The overriding parental response to the child's mix is clearly that of a translation. For this reason, it was classified as adult repetition rather than code-switching, despite the fact that a code-switch indeed occurs in the insertion sequence (cf. Lanza 2004: 270).

Of particular interest in a discussion of how caregiver responses to mixing may influence children's multilingual language acquisition was the fact that the 
data revealed two quite different types of adult repetition, namely one which was marked and indicated to the child that language choice was an issue, and one which was unmarked, and simply involved the adult incorporating the item in question into his or her own speech. The first functions as an 'other-repair', while the second is similar to moving on. These correspond to Döpke's 'translation' and 'incorporated translation' (1992: 63-64). In this study, I distinguish, wherever relevant, between adult repetition which is 'marked' and adult repetition which is 'incorporated'. An example of each is given in (9) and (10) respectively: ${ }^{5}$

(9) Lina (age 2;6.2) and aunt

@Situation: playing card game 'memory'

*LIN: CHU:ECHE.

\%eng: cake.

*AUN: that's a cake [!].

\%res: adult repetition, marked

*LIN: cake.

(10) Lina (age 2;4.8) and father

@Situation: playing with dolls

*LIN: ABZIE.

\%eng: take off.

*FAT: ABZIE. oui. <on va enlever la> [/] on va enlever la robe, et on va mettre autre chose. hm?

\%eng: take off. yes. <we'll take off the> [/] we'll take off the dress, and we'll put on something else. hm?

\%res: adult repetition, incorporated

*LIN: DA.

\%eng: there.

Note that example (10) also includes an instance of code-switching: a repetition of the child's mix followed by a translation of it. As with example (8), the overriding response was considered to be that of adult repetition.

\subsection{Moving on}

Although Lanza (2004: 266) shows that this response can be difficult to isolate, in the present data this was rarely the case. The only ambiguity was the occa-

5 Note that examples (6) and (7) are also instances of incorporated adult repetition, while example (8) is a marked adult repetition. 
sional case in which the adult continued with the conversation, but it was not clear whether he or she was 'exhibiting comprehension of the child's use of the other language' (Lanza 2004: 265) or not. The first case counts as moving on, the second as a non-response. Example (11) is a rare example of an unclear case:

(11) Lina (age 2;7.22) and father @Situation: playing a board game

*FAT: c'est la tête de l'ours. attends on va faire comme ça. écoute. \%eng: it's the head of the bear. wait we'll do it like this. listen.

*LIN: so [>] <MACHE $>$.

\%eng: make like this.

*FAT: $[<]<$ l'ours $>$ [/] l'ours te regarde. non d'abord ça. pas ça.

\%eng: the bear [/] the bear is looking at you. no first that. not that.

\%res: moving on

In this example, it is not actually clear whether the father is reacting to Lina's utterance so mache ('make like this') with his response non d'abord ça. pas ça. ('no first that. not that.'). Unclear cases, however, were counted as moving on, on the assumption that in these dyadic adult-child conversations, the adult is generally paying attention to the contributions of the child.

\subsection{Code-switching}

Code-switching following a child's mix was defined as any switch by the caregiver in his or her next turn, or an obvious repetition of the child's mix in a later turn. As already pointed out above, code-switches were only classified as such if they were not overridden by another response. The following is an example of a response classified as code-switching:

(12) Lina (age 2;4.8) and father @Situation: playing with dolls

*LIN: FERTIG \# BADE.

\%eng: finished \# bathing.

*FAT: ah ha. FERTIG BADE. alors <on va> [/] on va y mettre \# un pyjama, si on trouve le pyjama.

\%eng: ah ha. finished bathing. so <we'll> [/] we'll put on \# pyjamas, if we find the pyjamas.

\%res: code switching 


\subsection{No response to mixing}

In this study, all cases in which an adult did not respond to a child's mix were classified as a non-response. Although these instances were all coded, they are not given in the figures. A common reason for a non-response was a self-repair on the part of the child. Other reasons included the child starting a new topic herself or walking away. Also included within this category were the rare cases of an incomprehensible adult reply. Example (13) illustrates a non-response due to the child's self-repair:

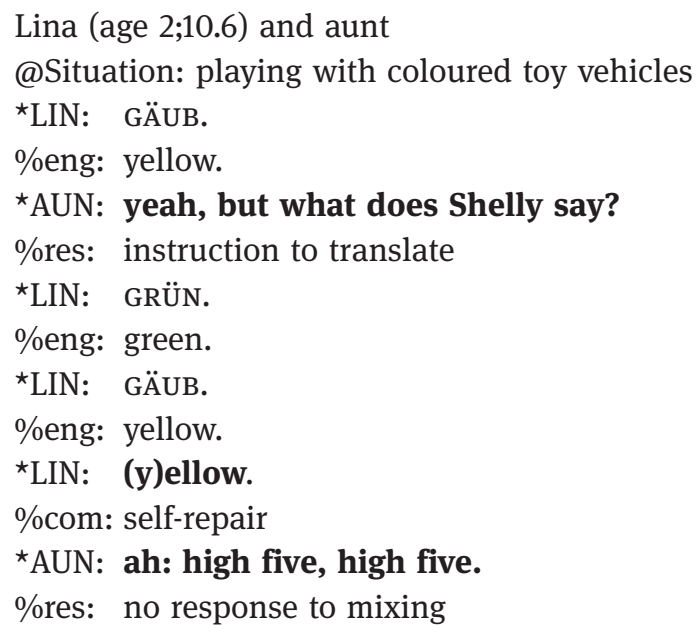

After Lina's first turn in this sequence, her aunt responds with an instruction to translate. Lina continues to name colours in Swiss German in her next turn but within the same turn repairs to English. Thus the aunt has no need to respond to Lina's mix since the child has already self-repaired. And in fact, in the aunt's next turn, she praises Lina's use of English.

\subsection{Special cases in coding}

A particular difficulty in the classification is illustrated by example (14). In this exchange, Lina utters the word for 'chicken' in Swiss German: huän. Her father does not understand, and guesses she may have been trying to say the French encore ('again', 'more'). From the father's perspective, he has not responded to a mix because he has not interpreted the utterance as a mix. However, from the child's perspective, he has attempted to guess what her utterance could be in the target language, and therefore this has been coded as an expressed guess: 
(14) Lina (age 2;2.17) and father @Situation: making objects out of play dough *LIN: HUÄN. \%eng: chicken.

*FAT: hein? tu veux encore? [pause of 2 seconds] encore quoi? \%eng: huh? you want more? [pause of 2 seconds] more what? \%res: expressed guess

*LIN: $\quad \mathrm{xxx}$

This same method of coding according to the child's perspective was applied consistently.

\subsection{Reactions to the three constraining responses}

Besides classifying the adults' responses to Lina's mixes, Lina's reactions to the adults' three constraining responses have also been examined in order to gain a fuller picture of the effectiveness of these. Nicoladis \& Genesee (1998: 87) also follow this path by examining whether there is a correlation between the parental responses and the child's choice of language in his next turn.

However, applying their exact method to my own data would result in an incorrect analysis in a number of cases, since the child sometimes responds in a later turn. This can be seen for example in the following extract:

(15) Lina (age 3;6.30) and father6

@Situation: looking at pictures (in a book or on cards)

*LIN: hm cat. (1)

*FAT: no. (2)

*LIN: hä? (3)

\%eng: huh?

^FAT: non. comment dit papa? cat c'est quoi [/-] ça c'est Shelly qui dit cat. (4)

\%eng: no. how does daddy say it? cat it's what [/-] it's Shelly who says cat.

\%res: instruction to translate

${ }^{\star}$ LIN: meow. (5)

\%com: onomatopoeia

6 Note that while this example is used for illustration, the response does not appear in the figures since the recording is at age three and a half, outside the main period of the study. 
*FAT: hm? (6)

${ }^{\star}$ LIN: m(e)ow. (7)

\%com: onomatopoeia, speech indistinct and quiet

*FAT: hm? c'est quoi? c'est un +..? (8)

\%eng: hm? it's what? it's a..+ ?

${ }^{\star}$ LIN: $\quad$ un $+\ldots$ (9)

^FAT: c'est quoi? (10)

\%eng: it's what?

*LIN: un chat. (11)

\%eng: a cat.

When Lina says cat (1), her father first denies this, switching to English himself, and simply saying no (2). (The switch is probably inadvertent, triggered by Lina's use of English.) This seems to confuse the child, who may not have understood that her choice of language was a problem; she responds with hä? ('huh?') (3). The father expands, invoking the one person-one language principle (4), and asking Lina what her father says for 'cat' (instruction to translate). Lina responds by producing the sound a cat makes (5). Her response is met with the questioning $h m$ ? (6), and Lina responds again with an onomatopoeic utterance (7), this time produced less distinctly and less confidently. Her father again prompts her to produce the word in French over two more turns (8 and 10), and in the end, Lina finally produces the item in the paternal language (11). The entire questioning of Lina's production of cat was counted as a single instruction to translate, and the final production of chat was counted as a production of the item in question in the paternal language. If only the language of the child's following turn had been considered (in this case, Lina's onomatopoeic utterance in turn 5 following the first instruction to translate), as in Nicoladis \& Genesee (1998), her actual response to the parent's strategy would have been missed. In the present study, the fact that a child may respond to a constraining strategy several turns later on is thus accounted for.

Note that Kasuya also looks at children's reactions to parental responses to mixing to see whether certain responses influence the child's 'next choice of language' (1998: 338). However, there is a difference between 'next choice of language' and a child's 'language choice in the next conversational turn' (Nicoladis \& Genesee 1998: 87). Calculating with the one or the other gives different results. In example (15), while Lina's 'language choice in the next conversational turn' is an onomatopoeic utterance, her 'next choice of language' is French. Nevertheless, I believe that even with 'next choice of language' certain responses to strategies will be missed. 


\section{Responses of Lina's father}

In this and the following section, the responses of Lina's father and aunt are examined. Table 1 lists the responses of Lina's father to turns by his daughter that contain lexical mixing. Following Lanza (2004: 272), only responses to lexical mixes are presented in the figures. Lexical mixes were defined as nouns, verbs, adjectives or blends (Lanza 2004: 215). ${ }^{7}$

\begin{tabular}{lrrrrrrr} 
Set & IT & MG & EG & AR & MO & CS & Total \\
\hline I & 0 & 0 & 0 & 4 & 1 & 1 & 6 \\
II & 0 & 3 & 2 & 5 & 1 & 10 & 21 \\
III & 0 & 1 & 0 & 9 & 13 & 0 & 23 \\
IV & 0 & 3 & 1 & 25 & 21 & 5 & 55 \\
V & 0 & 2 & 1 & 10 & 14 & 19 & 46 \\
VI & 0 & 2 & 3 & 31 & 21 & 10 & 67 \\
VII & 0 & 0 & 1 & 13 & 32 & 2 & 48 \\
VIII & 0 & 1 & 2 & 16 & 17 & 1 & 37 \\
IX & 0 & 2 & 4 & 13 & 12 & 5 & 36 \\
X & 0 & 0 & 1 & 10 & 21 & 2 & 34 \\
XI & 0 & 0 & 1 & 11 & 24 & 1 & 37 \\
XII & 0 & 1 & 0 & 6 & 16 & 0 & 23 \\
\hline Total & 0 & 15 & 16 & 153 & 193 & 56 & 433 \\
\hline Total \% & 0 & 3 & 4 & 35 & 45 & 13 & 100 \\
\hline
\end{tabular}

Table 1: Lina's father's responses following lexical mixing.

Key: IT: instruction to translate, MG: minimal grasp, EG: expressed guess, AR: adult repetition, MO: moving on, CS: code-switching

The most common response by Lina's father following his daughter's lexical mixing is to move on with the conversation, which he does 193 times out of 433 or 45 percent of the time. This sends the message to Lina that it is perfectly acceptable for her to use a non-paternal language.

The second most common response is that of adult repetition (153/433 or 35 percent). In table 2 I have divided these particular responses into repair-like or marked repetitions and incorporated adult repetitions.

We can see that over half of the responses involve incorporated adult repetition. The translated term is not marked in any way, and the child is not given

7 Thus, example (5), a response to a grammatical mix, does not appear in the figures. 


\begin{tabular}{lccc} 
Set & Marked & Incorporated & Total \\
\hline I & 2 & 2 & 4 \\
II & 2 & 3 & 5 \\
III & 5 & 4 & 9 \\
IV & 7 & 18 & 25 \\
V & 1 & 9 & 10 \\
VI & 18 & 13 & 31 \\
VII & 6 & 7 & 13 \\
VIII & 10 & 6 & 16 \\
IX & 10 & 3 & 13 \\
X & 0 & 10 & 10 \\
XI & 4 & 7 & 11 \\
XII & 4 & 2 & 6 \\
\hline Total & 69 & 84 & 153 \\
\hline$\%$ & 45 & 55 & 100 \\
\hline
\end{tabular}

Table 2: Two types of adult repetition used by Lina's father.

the idea that her language choice is an issue. In the following example, we can observe an instance of this type of adult repetition, as well as two codeswitches, which will be discussed further on:

(16) Lina (age 2;5.3) and father

@Situation: Lina is making a snail out of play dough

*FAT: [...] il n'a pas de tête ton escargot. tu veux lui donner une tête aussi?

\%eng: [...] it doesn't have a head your snail. do you want to give it a head too?

*LIN: AUG. (1)

\%eng: eye.

${ }^{\star} \mathrm{FAT}: \quad[>]<\mathrm{JA}>$ ?

$\%$ res: code-switching

*LIN: [<] <HIE AUG>. (2)

\%eng: here eye.

*FAT: AUG oui aussi. mais la tête surtout. hm?

\%eng: eye yes also. but the head above all. hm?

\%res: code-switching

*LIN: HIE AUG. (3)

\%eng: here eye.

^FAT: $\quad$ mhm. mais l'escargot <a deux $>$ [/], a deux yeux Lina. 
\%eng: mhm. but the snail has two, has two eyes Lina.

\%res: adult repetition, incorporated

In this example, Lina uses the Swiss German aug 'eye' three times before her father uses the equivalent French word. The first two times she uses the word, he responds by code-switching himself. After the third time he uses the French equivalent yeux 'eyes', but the translation is not marked in any way, and Lina is not made to feel that anything in her utterance was amiss. We see that the response is similar to moving on except that the child is exposed to the lexical item in the parental language.

Note that when her father does use adult repetition as a repair, Lina does not always interpret it as such. In the following example, Lina appears to be talking to herself, and asks herself a question in Swiss German. Her father translates her question into French, but Lina does not recognise this as a repair (or chooses not to recognise it as such), and simply answers the question:

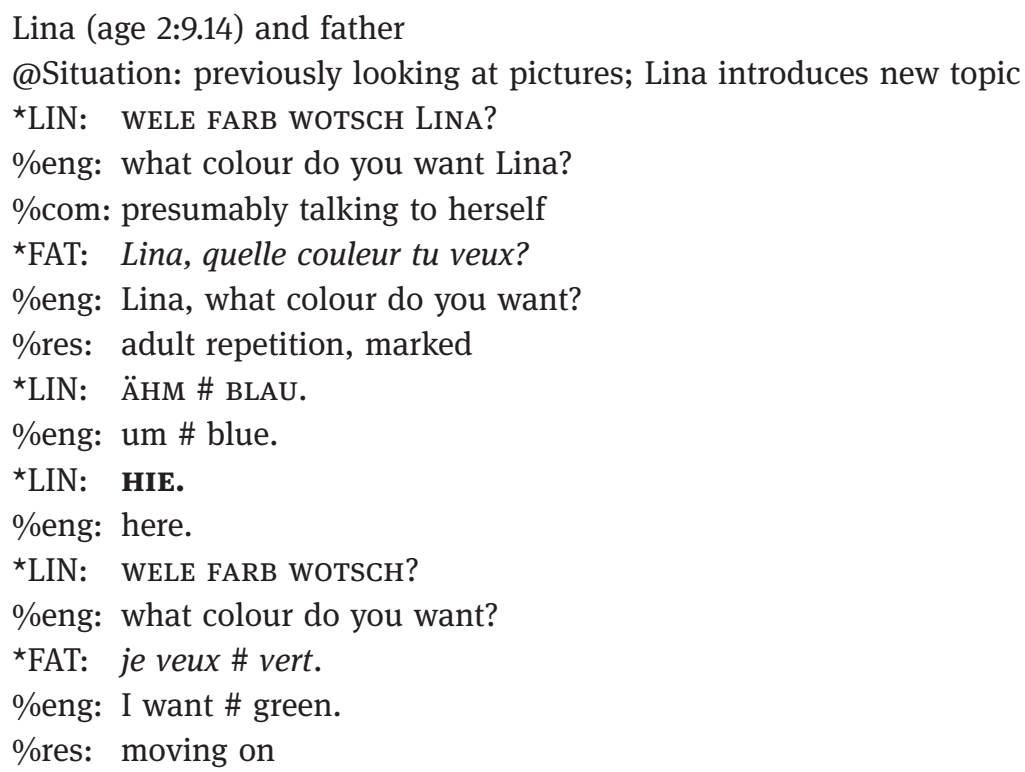

We see here an example of Lina's father consciously employing adult repetition as a strategy to try and impose the paternal language. However, we also see that the strategy is unsuccessful; Lina does not perceive her language choice to be a problem and simply responds to the question. Lina then repeats her question, now addressing her father, and this time her father does not attempt to translate it but answers it himself (moving on). 
The third most common response to Lina's mixing is code-switching (as seen in examples [12] and [16]): 56/433 instances (13 percent). This response is the one which most clearly encourages the use of the non-adult language, and diminishes any obligation on the part of the child to speak the adult's language: indeed why should she when the adult is willing to speak her language of preference?

With regard to the three constraining responses, we can observe few instances: no instructions to translate, fifteen minimal grasps and sixteen expressed guesses out of a total of 433 responses (3 percent and 4 percent respectively).

The minimal grasps often seem to be genuine instances of lack of comprehension. Certainly Lina rarely takes them as a cue to change languages (this occurs just once). Usually she repeats her utterance in the same or in a modified form (twelve times). There is one further instance in which she changes the content but continues in the non-paternal language, and one response which is incomprehensible.

It is imperative to examine how Lina's father reacts to her continued use of Swiss German after his minimal grasps. The exchanges reveal that usually a minimal grasp response on the part of the father is not one designed to promote the paternal language but rather, as stated above, an attempt to understand his daughter's utterance. This can be seen in the fact that once Lina has repeated her original utterance, her father is often satisfied with her reply. Twice he moves on after such a repetition, and five times he actually code-switches himself using the item in question. An example of the latter can be seen in (18):

(18) Lina (age 2;4.8) and father

@Situation: playing with dolls

*FAT: [...] c'est quoi [//] quelle couleur les cheveux?

\%eng: [...] it's what [//] what colour is her hair?

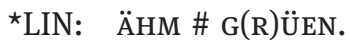

\%eng: um \# g(r)een.

^FAT: comment?

\%eng: pardon?

\%res: minimal grasp

\%com: father probably has not understood word due to missing $/ \mathrm{r} /$

*LIN: GRÜEN.

\%eng: green.

^FAT: non, ça c'est pas GRÜEN. c'est marron. [...]

\%eng: no, that's not green. it's brown. [...]

\%res: code-switching 
In the one instance where Lina does not repeat her utterance, but nevertheless continues in Swiss German, her father also code-switches. In sum, Lina continues in Swiss German following thirteen of her father's fifteen minimal grasp responses. In eight of these cases her father is satisfied with the response, and either moves on (twice) or code-switches (six times). In interaction with her father, therefore, Lina interprets minimal grasps as a cue to enunciate more clearly and not to change languages. Finally, let us note that in the other five cases of Lina's continuation in Swiss German, her father follows up with an expressed guess (twice) or adult repetition (three times). However, in none of these five cases does Lina produce the item in question in the target language.

Turning to Lina's father's expressed guess responses, we see that these do have the effect of Lina considering whether her father's expression in French is indeed the equivalent of her own. Of the sixteen expressed guesses, Lina responds in the affirmative in Swiss German or with $\mathrm{mhm}$ ten times. Her reactions to the other six expressed guesses are: repeating her original utterance (twice), moving on in the non-target language (twice), not replying (once) and giving a reply which is incomprehensible (once). Note that she never produces her father's language following his expressed guesses.

The recordings of Lina and her father reveal conversations which are what De Houwer has called 'dilingual' (2009: 361, adapted from Saville-Troike 1987), each interlocutor basically speaking a different language. Interestingly, Lina seems to have internalised this pattern to such an extent that when her Belgian grandmother comes to visit and speaks French to her, Lina commonly responds in Swiss German - a language her grandmother does not understand.

We see that Lina's father, via his responses to his daughter's mixing (summarised in table 1), allows a context to develop in which his daughter does not feel constrained to use her father's language, French. When his daughter uses Swiss German (or occasionally English), the most common response of Lina's father is simply to continue the conversation in French (moving on). Within his next most common response, adult repetition, more than half of his translations are unmarked; the lexical items are simply incorporated in his next turn (table 2). Such adult repetitions are thus also similar to moving on. His third most common response, code-switching, encourages his daughter's use of Swiss German. What I have termed 'constraining responses' are few and, since Lina has generally been given to understand that Swiss German is acceptable, do not usually have a constraining effect. Expressed guesses never lead to a response in French on the part of the child. Questioning of Lina's utterances via minimal grasps usually appears to be genuine since Lina's father is often satisfied with a repetition or clarification in Swiss German. Only once does Lina (choose to) interpret a minimal grasp as a cue to change languages. Finally, Lina's father 
never responds to a mix with an instruction to translate. Lina, on the other hand, does try to influence her father to speak Swiss German, as can be seen in the extract below. In this conversation, Lina is trying to get her father to remember an incident in Berne, but he has no idea of what she is talking about. He misunderstands her use of the Swiss German word erinnere, which Lina is using to mean 'remember', and interprets it instead as 'remind':

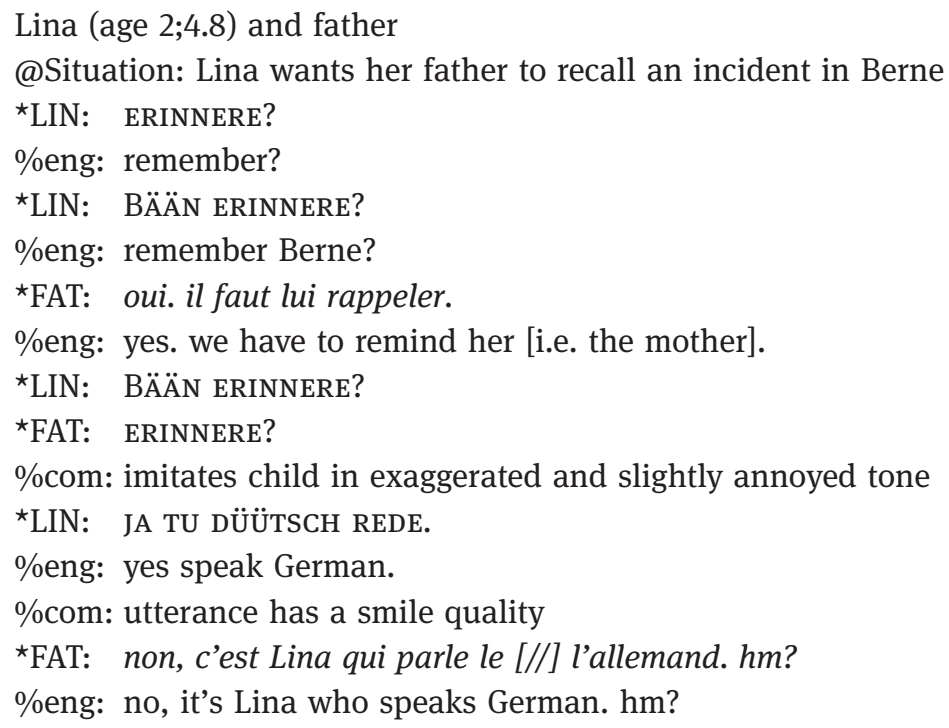

When Lina's father imitates her with his utterance erinnere, the child does not notice his annoyed tone of voice but rather his choice of language - which greatly pleases her. We hear a smile quality in her speech as she states 'yes speak German'. (Note that in theory, this utterance could also be interpreted as 'yes you speak German', in which tu is interpreted as 'you' rather than 'do'. In this interpretation, the Swiss German utterance would be in a non-target form, since the verb rede 'speak' is in the infinitive.) Her father does not comply, and immediately switches back to French; however, he states that it is his daughter who speaks German - thereby underlining the language choice already evident.

Besides the recordings, information on interactional styles was gained from the informal interviews. In one such interview, in the seventh month of the study, Lina's mother expressed disappointment at Lina's lack of production in French. The mother mentioned that Lina's father had, for a short time, tried to insist on her use of French by pretending not to understand (minimal grasp strategy) but that he had quickly abandoned this because Lina had stopped talking (these attempts are not evident in the recordings). Lina's father had 
explained his abandoning of the strategy to his wife with the reasoning that the most important thing for him was to be able to communicate with his child. Faced with a breakdown of communication, he chose to allow his daughter to express herself in whatever language she pleased.

\section{Responses of Lina's aunt}

The responses of Lina's aunt to her niece's lexical mixing can be seen in table 3 .

I discuss the responses here in order from most constraining to least constraining. Instruction to translate is the second most common response of Lina's

\begin{tabular}{lccccccc} 
Set & IT & MG & EG & AR & MO & CS & Total \\
\hline I & 0 & 7 & 8 & 8 & 7 & 0 & 30 \\
II & 0 & 1 & 1 & 4 & 0 & 0 & 6 \\
III & 1 & 0 & 1 & 5 & 0 & 0 & 7 \\
IV & 0 & 3 & 4 & 7 & 2 & 0 & 16 \\
V & 2 & 4 & 3 & 12 & 2 & 0 & 23 \\
VI & 8 & 4 & 2 & 9 & 3 & 0 & 26 \\
VII & 5 & 1 & 2 & 10 & 1 & 0 & 19 \\
VIII & 3 & 2 & 6 & 13 & 6 & 0 & 30 \\
IX & 5 & 2 & 4 & 21 & 3 & 0 & 35 \\
X & 6 & 1 & 3 & 13 & 7 & 0 & 30 \\
XI & 7 & 3 & 2 & 6 & 2 & 0 & 20 \\
XII & 10 & 0 & 1 & 14 & 7 & 0 & 32 \\
\hline Total & 47 & 28 & 37 & 122 & 40 & 0 & 274 \\
\hline Total $\%$ & 17 & 10 & 14 & 45 & 15 & 0 & 101 \\
\hline
\end{tabular}

Table 3: Lina's aunt's responses following lexical mixing.

Key: IT: instruction to translate, MG: minimal grasp, EG: expressed guess, AR: adult repetition, MO: moving on, CS: code-switching

aunt. The success of this strategy can be seen in Lina's replies. In 32/47 instances (68 percent), Lina responds by translating the item into the target language. We can observe how internalised this pattern has become in the following example (the aunt frequently uses it for grammatical mixes as well, the figures for which do not appear here). In this example, the aunt does not even need to finish her instruction before Lina starts to translate: 
(20) Lina (age 2;10.26) and aunt

@Situation: looking at a picture book

*LIN: AFF.

\%eng: monkey.

*AUN: what does Shelly [>] < say $>$ ?

*LIN: [<] <monk>ey.

These results are interesting in the light of Kasuya's findings (1998: 337), who separated her two explicit strategies (instruction to translate and correction plus elicitation) from the others and found that children were more likely to use the parental language after an explicit strategy than any other type of parental response.

Turning to the minimal grasp response, which is not explicit and may be ambiguous, Lina responds similarly with her aunt as with her father. That is, she usually repeats her original utterance (19/28 times or 68 percent) or otherwise continues in Swiss German (four times). Only once does Lina take the minimal grasp response of her aunt as a cue to change languages. A further two responses are incomprehensible, and two are not assignable to a particular language. Interestingly, the only time in which Lina takes a minimal grasp response on the part of her aunt as a cue to change to English is following the one French mix in this set of 28. French is a language Lina's aunt does not master, and it is likely that Lina realises that language choice is the issue here:

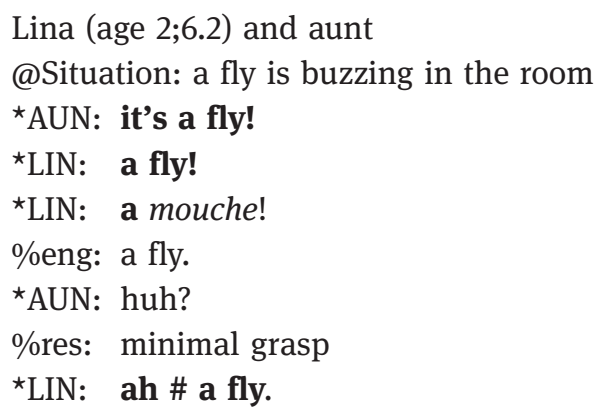

In terms of the promotion of English, it is important to examine how Lina's aunt reacts to the child's continuation in Swiss German after a minimal grasp response. Unlike Lina's father, her aunt frequently keeps insisting on English so that in ten cases out of 28 , Lina does finally produce the item in question. Six of these cases involve a follow-up with adult repetition, four cases an instruction to translate. An example of each can be observed in (22) and (23) respectively: 
(22) Unsuccessful minimal grasp response followed by adult repetition:

Lina (age 2;5.3) and aunt

@Situation: pretend cooking

*LIN: KOMM SITZE

\%eng: come sit.

*AUN: huh?

\%res: minimal grasp

${ }^{\star}$ LIN: SITZE.

${ }^{\star}$ AUN: sit.

\%res: adult repetition, marked

${ }^{\star}$ LIN: sit.

(23) Unsuccessful minimal grasp followed by instruction to translate:

Lina (age 2;6.2) and aunt

@Situation: playing card game 'memory'

*AUN: wow. what is that?

*LIN: BÜSELI.

\%eng: little cat.

*AUN: a what [!]?

\%res: minimal grasp

${ }^{\star}$ LIN: BÜsI.

\%eng: cat.

*AUN: and what does Shelly say?

\%res: instruction to translate

${ }^{\star} \mathrm{LIN}$ : cat.

*AUN: ah. good. cat. the cat \# and the hat. slept on a mat.

The next most constraining response, the expressed guess, is used by Lina's aunt 37/274 times or 14 percent. After two of the responses, Lina immediately switches to English. Seven times she does not respond, two responses are ambiguous, and one is incomprehensible. In most cases (25) Lina continues either in Swiss German or with a non-language-assignable affirmation $(\mathrm{mhm}$, etc.). As with the minimal grasp response above, Lina's aunt does not always accept the responses in Swiss German and sometimes keeps insisting on English. In five cases she is successful, so that Lina does eventually produce the item in question. An example is given below:

(24) Lina (age 2;9.10) and aunt @Situation: drawing and writing *LIN: XXX ICH SCHRIIBE ÖPPIS. \%eng: xxx I'm writing something. 
*AUN: you wanna write something?

\%res: expressed guess

*LIN: JA.

*AUN: so. I:, \# I: +...

${ }^{\star}$ LIN: I: +...

*AUN: wa:nt +...

*LIN: wa:nt + ...

${ }^{\star}$ AUN: to:...+

${ }^{\star}$ LIN: to: + ...

*AUN: [>] <wri:te $>+. .$.

${ }^{\star}$ LIN: $[<]<$ wri:te $>+. .$.

${ }^{\star}$ AUN: something.

${ }^{\star}$ LIN: something.

Note that although Lina is repeating most of the words of the sentence one after the other, she does produce the key lexical item write at the same time as her aunt, which shows that she does actually know the word.

An examination of Lina's aunt's 'follow-ups' after unsuccessful minimal grasp and expressed guess responses shows the importance of looking at an entire conversational sequence, and not just picking out and adding up the individual strategies and the children's responses to them. Simply tallying adult response to mixing + child response would obscure how Lina's aunt insists on the child's use of English.

\begin{tabular}{lccc} 
Set & Marked & Incorporated & Total \\
\hline I & 8 & 0 & 8 \\
II & 3 & 1 & 4 \\
III & 5 & 0 & 5 \\
IV & 6 & 1 & 7 \\
V & 11 & 1 & 12 \\
VI & 9 & 0 & 9 \\
VII & 10 & 0 & 10 \\
VIII & 10 & 3 & 13 \\
IX & 21 & 0 & 21 \\
X & 11 & 2 & 13 \\
XI & 6 & 0 & 6 \\
XII & 12 & 2 & 14 \\
\hline Total & 112 & 10 & 122 \\
\hline$\%$ & 92 & 8 & 100 \\
\hline
\end{tabular}

Table 4: Two types of adult repetition used by Lina's aunt. 
Adult repetition is the response Lina's aunt uses by far the most following a lexical mix: 44 percent (122/274) of her responses fall into this category. The most important aspect to note here is that most of these translations, namely 92 percent, are marked or repair-like (see table 4). Examples (9) and (22), above, illustrate Lina's aunt's marked adult repetition. In both examples, we see that Lina repeats the word in question. Examples (6) and (7), also above, are examples of her incorporated adult repetitions.

The most frequent response by Lina's father, moving on, is only the third most frequent response of her aunt. Moreover, an examination of the content of the aunt's turns when she moves on reveals much promotion of English. In the following extract, for example, we see that Lina's aunt does not translate Lina's lexical mix because she wants to teach the child the more appropriate term:

(25) Lina (age 2;10.26) and aunt

@Situation: looking at a picture book of animals

*AUN: what are they doing?

*LIN: RIITE.

\%eng: riding.

*AUN: they're \# galloping.

\%res: moving on

*LIN: JA.

${ }^{\star} \mathrm{AUN}$ : can you say that? galloping.

${ }^{\star} \mathrm{LIN}$ : galloping.

*AUN: good.

In this exchange, I interpret the pause after they're as the aunt probably stopping herself from translating riite, 'riding', and looking for the semantically appropriate term galloping, which she then gets the child to repeat. In the next example of moving on, we see Lina's aunt ignoring one mix in order to focus on the child's production of a different word:

(26) Lina (age 2;6.2) and aunt

@Situation: playing card game 'memory'

*AUN: what's $[>]<$ this $>$ ?

${ }^{\star}$ LIN: $[<]<$ LUEG $>$.

\%eng: look.

*LIN: frog.

*AUN: yeah, frog. good.

\%res: moving on 
It appears that in this exchange, the attention-getting utterance lueg is for the aunt less important than the names of objects. She does not repair lueg, but concentrates on praising Lina's next utterance, which is the English noun frog.

Finally, we can observe a complete absence of the least constraining response, code-switching. The response which is most likely to detract from the imposition of one particular language is not used by Lina's aunt at all.

\section{Summary and conclusion}

The responses of the two caregivers are given again for comparative purposes in a single table below. Note that the two types of adult repetition are distinguished here.

\begin{tabular}{|c|c|c|c|c|}
\hline \multirow[t]{2}{*}{ Response } & \multicolumn{2}{|c|}{ LIN FAT } & \multicolumn{2}{|c|}{ LIN AUN } \\
\hline & N & $\%$ & N & $\%$ \\
\hline Instruction to translate & 0 & 0 & 47 & 17 \\
\hline Minimal grasp & 15 & 3 & 28 & 10 \\
\hline Expressed guess & 16 & 4 & 37 & 14 \\
\hline Adult rep. marked & 69 & 16 & 112 & 41 \\
\hline Adult rep. incorporated & 84 & 19 & 10 & 4 \\
\hline Moving on & 193 & 45 & 40 & 15 \\
\hline Code switching & 56 & 13 & 0 & 0 \\
\hline Total & 433 & 100 & 274 & 101 \\
\hline
\end{tabular}

Table 5: Responses of Lina's father and aunt to her lexical mixing.

We have seen that in the case of Lina's aunt, the strategy most used is that of marked adult repetition, that is adult repetition functioning as a repair. Lina's aunt uses this strategy in 41 percent of all her responses to Lina's mixing. In this way, Lina is provided with vocabulary in English, while at the same time being reminded that she should use this vocabulary. Lina's father, on the other hand, uses this strategy only 16 percent of the time, his predominant response to Lina's mixing being moving on, which occurs in 45 percent of all cases. Figures 2-3 illustrate these findings.

These figures further illustrate how the rest of the responses of Lina's aunt overall cluster at one end of the scale, namely the monolingual end. The three constraining responses, instruction to translate, minimal grasp and expressed 


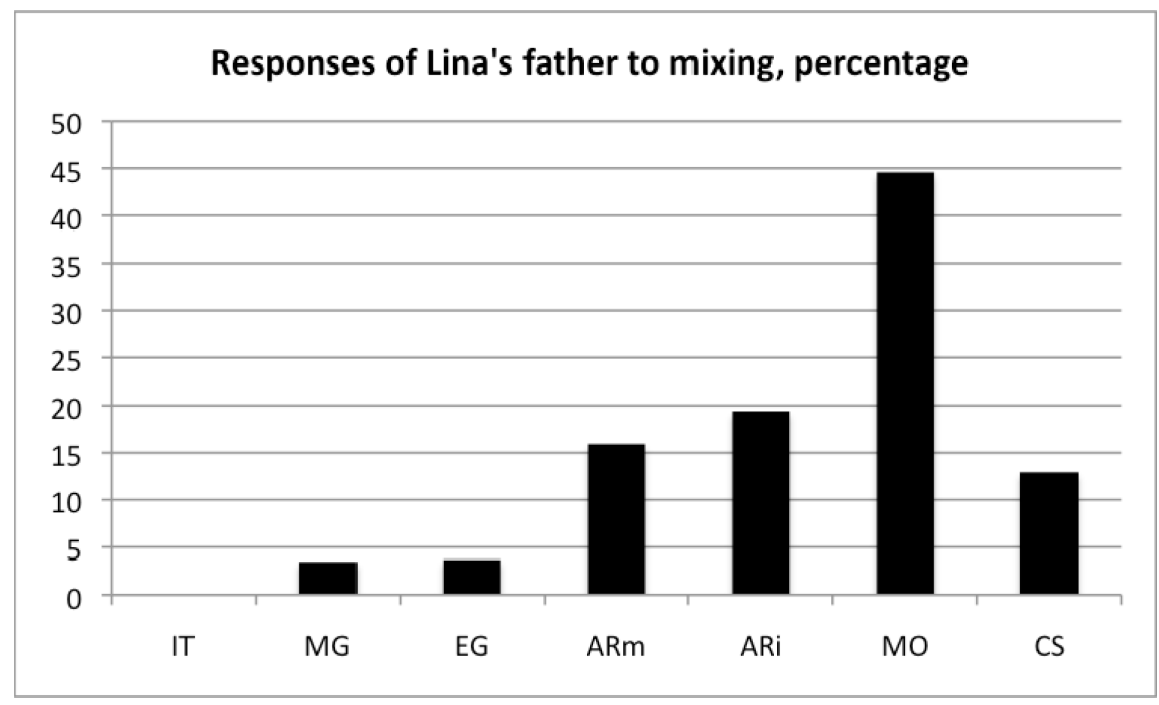

Figure 2: Responses of Lina's father to mixing, percentage.

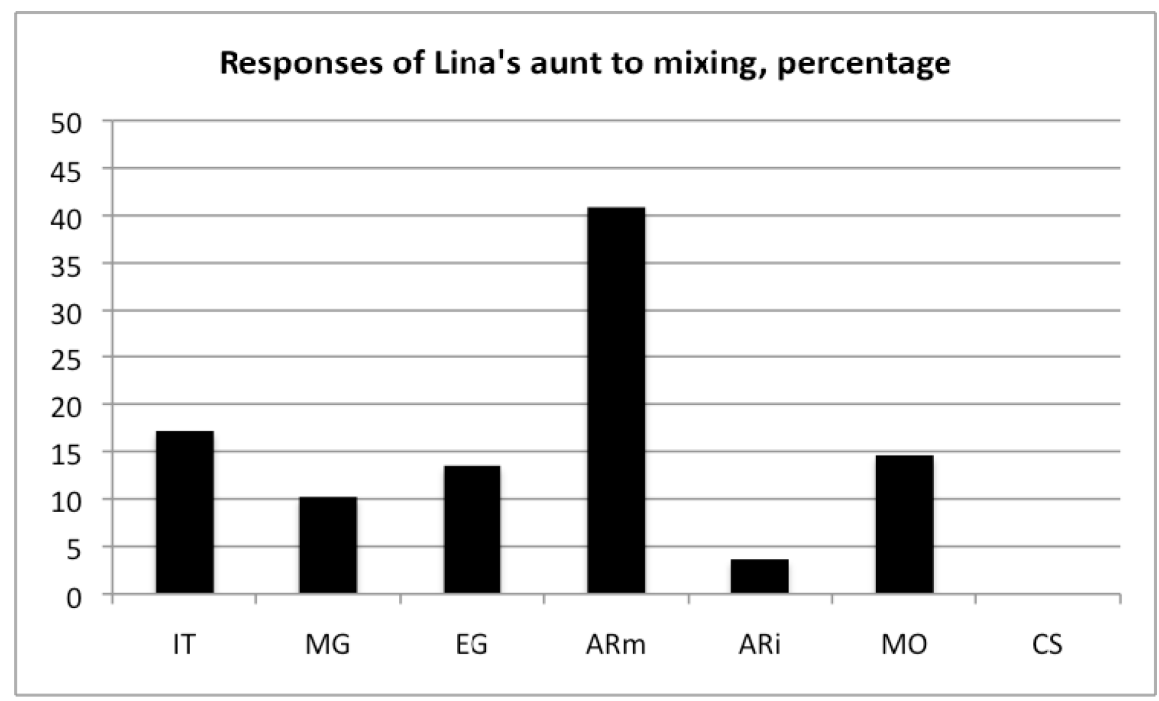

Figure 3: Responses of Lina's aunt to mixing, percentage.

Key: IT: instruction to translate, MG: minimal grasp, EG: expressed guess, ARm: adult repetition, marked, ARi: adult repetition, incorporated, MO: moving on, CS: code switching 
guess comprise 41 percent of her responses to Lina's mixing. Among the responses of Lina's father, on the other hand, these only make up 7 percent.

The findings in this paper thus demonstrate that if the goal is active trilingualism, languages for which there is considerably less input need to be promoted actively in conversation. Lina's aunt did this, teaching Lina vocabulary via her frequent use of marked adult repetition, and eliciting vocabulary from Lina with her instructions to translate. Lina's father, on the hand, allowed dilingual conversations to become the norm.

Of course, further language input factors must be considered. English is the language of communication of Lina's parents, and the couple language is not a negligible factor in a trilingual child's language development. The regular exposure as well as the prestige of the parental lingua franca in the eyes of the child both play a role (cf. Barnes 2006: 10-11, 91; Cruz-Ferreira 2006: 34). Certainly, the importance of English as a home language for Lina is evidenced by various instances in which she addresses her father in English. Thus, the parents' choice of English as their language of communication clearly supports Lina's acquisition of English. On the other hand, it must be remembered that Lina has considerably more interaction in French than in English. Thus, it might be expected that she produce at least as much French as English. We have seen, however, that this is not the case - and that the explanation lies in the caregivers' different conversational styles.

As a final point, I would like to reflect on the reasons for the different levels of insistence of Lina's father and aunt. Their different interactional styles can partially be ascribed to their different goals and roles in interaction with the child. Lina's aunt clearly wants her niece to speak English and takes on a teaching role. As she has stated, she takes pride in the advances of her niece in English. For Lina's father, however, his primary goal, as he himself stated, is to be able to communicate with his daughter. It seems evident that unhampered communication is more vital for a parent than a relative further removed, since there is more at stake. Lina's aunt can 'afford' to risk communication breakdown because their relationship is not as close as that of a parent and child. Lina's father, on the other hand, does not want to take such a risk. For the same reason, namely the difference in the levels of closeness in the two relationships, Lina's aunt can give priority to her role as a teacher if she so pleases. However, for Lina's father, his role as a parent is far more important than that of a language instructor.

To conclude, we have seen, on the one hand, how influential particular caregiver responses are in fostering a non-dominant language. On the other hand, however, we have also seen why a parent may find it difficult and ultimately choose not to follow the path of insistence. 


\section{Acknowledgements}

I would like to thank the two anonymous reviewers of this paper for their very helpful comments and suggestions. I would further like to acknowledge funding for this project by the University of Zurich.

\section{Bionote}

Sarah Chevalier is Lecturer in English Linguistics at the University of Zurich. Her research interests are in multilingualism, language acquisition, conversation analysis and sociolinguistics. Publications include an analysis of personal naming practices in Australia (Ava to Zac: A sociolinguistic study of given names and nicknames in Australia, Francke 2006) and an edited volume of papers devoted to aspects of lexis and discourse (Words, words, words: Philology and beyond, Francke 2012).

\section{Appendix}

Transcription conventions (based on MacWhinney 2011)

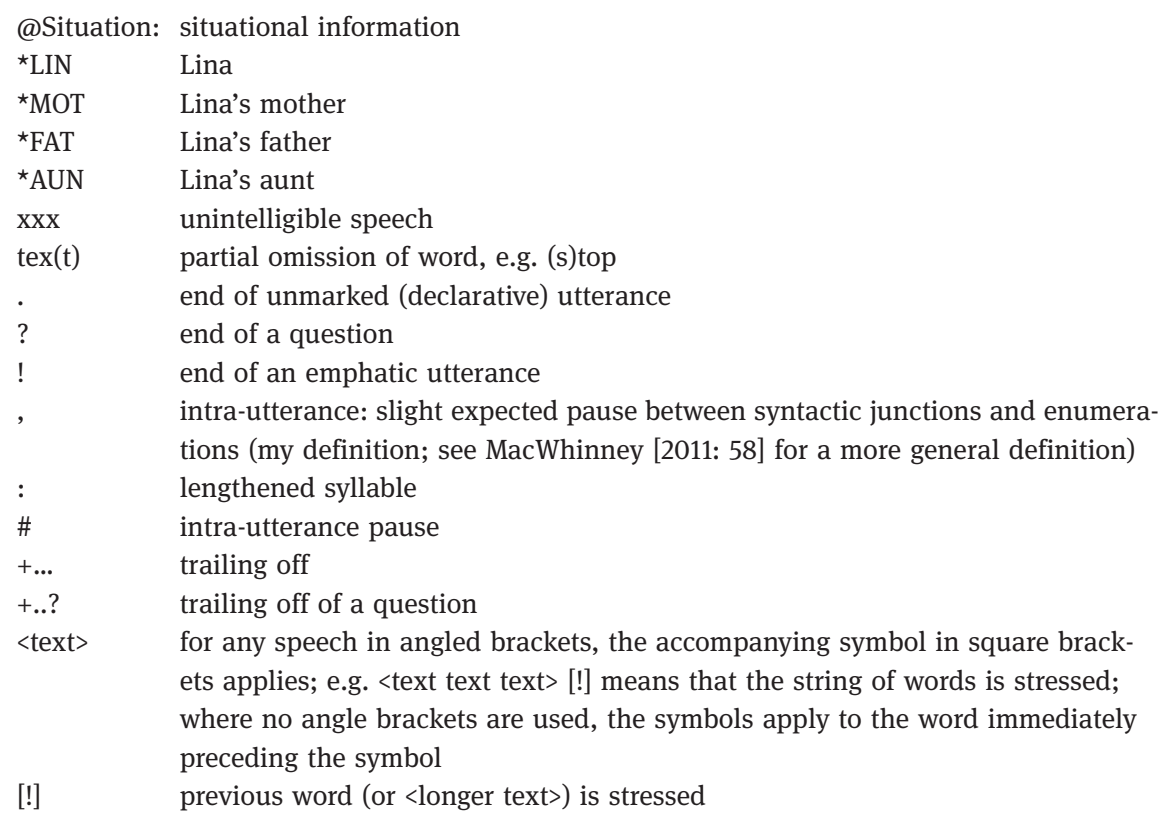
ets applies; e.g. <text text text> [!] means that the string of words is stressed; where no angle brackets are used, the symbols apply to the word immediately preceding the symbol

[!] previous word (or <longer text $>$ ) is stressed 
[?] best guess at a word (or <longer text>)

[>] overlap follows

$[<] \quad$ overlap precedes

[/] retracing without correction (repetition)

[//] retracing with correction; in this study, this symbol is also used for retracing involving a change of languages

[/-] false start without retracing

[text] transcriber's comments when they happen to appear in the main speech line

[...] speech omitted from the example presented

\%com: comment

\%eng: $\quad$ English translation (idiomatic)

\%pho: phonology

\%res: $\quad$ response to mixing

\section{References}

Barnes, Julia. 2006. Early trilingualism: A focus on questions. Clevedon: Multilingual Matters.

Barnes, Julia. 2011. The influence of child-directed speech in early trilingualism. International Journal of Multilingualism 8(1). 42-62.

Cenoz, Jasone \& Fred Genesee (eds.). 2001. Trends in bilingual acquisition. Amsterdam: John Benjamins.

Chevalier, Sarah. 2008. Contextual aspects of early trilingualism. In Alexandre Nikolaev \& Jussi Niemi (eds.), Two or more languages: Proceedings from the $9^{\text {th }}$ Nordic Conference on Bilingualism, August 10-11, 2006, Joensuu (Studies in Languages 43), 37-46. Joensuu, Finland: University of Joensuu.

Cohen, James, Kara T. McAlister, Kellie Rolstad \& Jeff MacSwan (eds.). 2005. ISB4: Proceedings of the $4^{\text {th }}$ International Symposium on Bilingualism. Somerville, MA: Cascadilla Press.

Cruz-Ferreira, Madalena. 2006. Three is a crowd? Acquiring Portuguese in a trilingual environment. Clevedon: Multilingual Matters.

De Houwer, Annick. 2009. Bilingual first language acquisition. Bristol: Multilingual Matters.

Dewaele, Jean-Marc. 2000. Trilingual first language acquisition: Exploration of a linguistic 'miracle'. La Chouette. 41-45.

Dewaele, Jean-Marc. 2007. Still trilingual at ten: Livia's multilingual journey. Multilingual Living Magazine March/April. 68-71.

Doherty-Sneddon, Gwyneth. 2003. Children's unspoken language. London: Jessica Kingsley.

Döpke, Susanne. 1992. One parent one language: An interactional approach. Amsterdam: John Benjamins.

Hoffmann, Charlotte. 1985. Language acquisition in two trilingual children. Journal of Multilingual and Multicultural Development 6(6). 479-495.

Juan-Garau, Maria \& Carmen Pérez-Vidal. 2001. Mixing and pragmatic parental strategies in early bilingual acquisition. Journal of Child Language 28. 59-86.

Kasuya, Hiroko. 1998. Determinants of language choice in bilingual children: The role of input. The International Journal of Bilingualism 2(3). 327-346.

Kazzazi, Kerstin. 2007. 'Man se tā baladam'. 'Language awareness in a trilingual child'. Paper presented at the L3 conference, Stirling, Scotland, 3-5 September. 
Kazzazi, Kerstin. 2011. 'Ich brauche mix-cough': Cross-linguistic influence involving German, English and Farsi. International Journal of Multilingualism 8(1). 63-79.

Kendon, Adam. 2004. Gesture: Visible action as utterance. Cambridge: Cambridge University Press.

Lanza, Elizabeth. 2004 [1997]. Language mixing in infant bilingualism: A sociolinguistic perspective. Second edn. Oxford: Oxford University Press.

MacWhinney, Brian. 2011. The CHILDES project tools for analyzing talk - electronic edition. Part 1: The CHAT transcription format. <http://childes.psy.cmu.edu/manuals/chat.pdf> (accessed 17 March 2011).

Montanari, Simona. 2005. 'Sol! GANDA, cute!': A longitudinal study of language choice in a developing trilingual child. In James Cohen, Kara T. McAlister, Kellie Rolstad \& Jeff MacSwan (eds.), ISB4: Proceedings of the $4^{\text {th }}$ International Symposium on Bilingualism, 1662-1678. Somerville, MA: Cascadilla Press.

Montanari, Simona. 2010. Language differentiation in early trilingual development: Evidence from a case study. Saarbrücken, Germany: Verlag Dr. Müller.

Nicoladis, Elena \& Fred Genesee. 1998. Parental discourse and codemixing in bilingual children. The International Journal of Bilingualism 2(1). 85-99.

Nikolaev, Alexandre \& Jussi Niemi (eds.). 2008. Two or more languages: Proceedings from the $9^{\text {th }}$ Nordic Conference on Bilingualism, August 10-11, 2006, Joensuu. Joensuu, Finland: University of Joensuu.

Piller, Ingrid. 2002. Bilingual couples talk. Amsterdam: John Benjamins.

Quay, Suzanne. 2001. Managing linguistic boundaries in early trilingual development. In Jasone Cenoz \& Fred Genesee (eds.), Trends in bilingual acquisition, 149-199. Amsterdam: John Benjamins.

Quay, Suzanne. 2008. Dinner conversations with a trilingual two-year-old: Language socialization in a multilingual context. First Language 28(1). 5-33.

Saville-Troike, Muriel. 1987. Dilingual discourse: The negotiation of meaning without a common code. Linguistics 25(1). 81-106.

Schmid, Stephan. 2010. Segmental features of Swiss German ethnolects. Paper presented at the Sociophonetics at the Crossroads of Speech Variation, Processing and Communication Conference, Scuola Normale Superiore Pisa, 14-15 December.

Wang, Xiao-lei. 2008. Growing up with three languages. Birth to eleven. Bristol: Multilingual Matters. 